\title{
Sosialisasi Pemilihan Sampah Rumah Tangga untuk Meningkatkan Pengetahuan Anak-anak dalam Pengolahan Sampah di Yatim Piatu Muhammadiyah Tanah Abang
}

\author{
Mega Puspa Sari ${ }^{1}$, Nia Musniati ${ }^{1}$, Roudhatul Zannah ${ }^{1}$, Assya Zazhilla ${ }^{1}$ \\ ${ }^{1}$ Fakultas Ilmu-ilmu Kesehatan, Universitas Muhammadiyah Prof. Dr. Hamka, Jl. Limau II No.3, RT.3/RW.3, Kramat \\ Pela, Kec. Kby. Baru, Kota Jakarta Selatan, Daerah Khusus Ibukota Jakarta 12130 \\ *Email koresponden: ns.megapuspasari@uhamka.ac.id
}

\section{ARTICLE INFO}

Article history

Received: 24 Apr 2020

Accepted: 25 Mar 2021

Published: 23 Apr 2021

\section{Kata kunci:}

Anorganik

Organik

Pemilahan sampah

\section{Keywords:}

Garbage selection

Inorganic

Organic

\begin{abstract}
A B S T R A K
Background: Panti Asuhan Muhammdiyah Tanah Abang memiliki 2 jenis tempat sampah berdasarkan fungsinya yaitu tempat sampah berwarna biru yang fungsinya untuk sampah organik, sampah basah seperti sisa - sisa makanan, dedaunan, dan lainnya. Tempat sampah berwarna orange yang fungsi sebenarya untuk sampah anorganik, sampah kering, kertas, kaleng, plastik, dan lainnya. Namun, dalam penggunaannya tempat sampah di panti belum sesuai dengan jenisnya. Kurangnya pengetahuan anak-anak panti tentang kebermanfaatan sampah serta tidak adanya pembiasaan dalam pemilah sampah ini menjadi faktor utama menumpuknya sampah. Tujuan pengabdian masyarakat ini meningkatkan pemahaman anak-anak tentang sampah organik dan anorganik dan meningkatkan kesadaran dalam mebiasakan perilku hidup bersih terutama dalam memilah sampah. Metode: Program pengabdian masyarakat dilakukan di Panti Asuhan Muhammadiyah Tanah Abang Jakarta Pusat, pada Bulan Januari - April, kegiatan ini diikuti oleh 14 orang anak-anak panti. Metode pelaksanaan kegiatan dibagi menjadi dua tahap yaitu: penyuluhan untuk meningkatkan pengetahuan dan permainan (games) untuk meningkatkan keterampilan. Hasil: Berdasarkan hasil pre dan post-test dari 12 orang anak-anak panti didapatkan adanya peningkatan pengetahuan anak-anak panti tentang pemilahan sampah dari 66,7\% menjadi 91,7\%. Kesimpulan: Setelah dilakukan kegiatan ini diharapakan dapat dilanjutkan dengan pelatihan pengolahan sampah baik itu pengolahan sampah organik dan anorganik.
\end{abstract}

\section{A B S T R A C T}

Background: The Tanah Abang Muhammadiyah Orphanage has 2 types of trash based on its function, namely the blue trash can whose function is for organic waste, wet waste such as food scraps, leaves, and others. Orange colored trash cans that actually function for inorganic waste, dry trash, paper, cans, plastics, and others. However, in its use, the trash cans in the orphanage are not yet the correct type. Lack of knowledge of the orphanage children about the usefulness of waste and the absence of habituation in sorting waste are the main factors in accumulating garbage. The aim of this community service is to increase children's understanding of organic and inorganic waste and to increase awareness in getting my behavior to live clean, especially in sorting waste. Methods: The community service program was carried out at the Muhammadiyah Tanah Abang Orphanage, Central Jakarta, from January to April, this activity was attended by 14 orphanage children. The method of implementing the activity is divided into two stages, namely: counseling to increase knowledge and games to improve skills. Results: Based on the pre and post-test results of the 12 orphanages, it was found that there was an increase in the orphanage's knowledge about sorting waste from $66.7 \%$ to 
to $91.7 \%$. Conclusions: After this activity is carried out, it is hoped that it can be continued with waste management training, both in organic and inorganic waste processing.

(c) 2021 by authors. Lisensi Jurnal Solma, UHAMKA, Jakarta. Artikel ini bersifat open access yang didistribusikan di bawah syarat dan ketentuan Creative Commons Attribution (CC-BY) license.

\section{PENDAHULUAN}

Sampah masih menjadi permasalahan manusia yang tidak bisa dilepaskan dari kegiatan sehari-hari. Pengelolaan sampah dalam pasal 1 menyebutkan bahwa sampah adalah sisa kegiatan sehari-hari manusia dan/atau proses alam yang berbentuk padat (Istiqamah et al., 2019). Sampah secara sederhana dapat diartikan sebagai segala barang padat yang tidak terpakai lagi. Seringkali sampah menimbulkan masalah yang serius jika tidak dikelola dengan tepat. Sampah terbagi menjadi sampah organik dan anorganik (Taufiq \& Maulana, 2015). Sampah organik sampah yang dapat terurai secara sempurna dengan sendirinya melalui proses biologi baik aerob maupun anaerob. Sampah organik memiliki ciri mudah membusuk dan mempunyai sifat kimia yang stabil sehingga zatnya akan mengendap ke dalam tanah, dasar sungai, danau serta laut dan mempengaruhi ekosistem di dalamnya. Sampah organik dapat mengalami dekomposisi dan menjadi kompos. Sebaliknya sampah anorganik adalah sampah yang tidak bisa terurai oleh proses biologi. Sampah ini dapat terurai secara alami namun dalam waktu yang sangat lama (Dinas Lingkungan Hidup Kabupaten, 2020).

Minimnya pengetahuan tentang kebermanfaatan sampah ini menjadi faktor utama menumpuknya sampah. Sampah yang seharusnya bisa dimanfaatkan dan dipisah menjadi sampah organik dan sampah anorganik tidak ditangani dengan benar (Marliani, 2015). Sampah harus mendapat perhatian yang serius dari instansi yang bertanggung jawab disetiap daerah untuk mencegah atau memperkecil pencemaran yang dapat ditimbulkan. Sampah yang terus bertambah, membuat sebagian orang berfikir dan melakukan aksi nyata bagaimana caranya mengatasi sampah. Rumah tangga menjadi pemberi sampah terbanyak sekitar $75 \%$ dari total volume sampah di Indonesia (Ramon \& Afriyanto, 2017). Sampah rumah tangga adalah sampah yang berasal dari kegiatan sehari-hari dalam rumah tangga yang tidak termasuk tinja dan sampah spesifik. Sampah rumah tangga tidak berasal dari rumah tangga namun, berasal dari kawasan pemukiman, kawasan komersial, kawasan industry, kawasan khusus, fasilitas umum, fasilitas sosial, dan / fasilitas lainnya (Mckee \& Perdana, 2018).

Pembiasaan memilah sampah akan memberikan kemudahan dalam pengolahan sampah. Pemilahan sampah adalah kegiatan mengelompokkan dan memisahkan sampah dengan jenis sampah (Intruksi Gubernur No. 107, 2019). Sampah yang tidak terurus akan menyebabkan beragam masalah jika tidak ditangani dengan baik, seperti masalah kesehatan maupun masalah keindahan lingkungan. Sebagai lembaga membentuk perkembangan anak-anak panti Asuhan harus mampu membiasakan anak-anak panti menjaga lingkungan di sekitar panti agar nyaman, bersih, dan indah. Peran serta warga Panti Asuhan seperti Bapak / Ibu Kepala Panti, dan Pengasuh, dalam memberikan pengetahuan kepada anak-anakdi panti dimulai dari usia dini. Pembiasan dan keteladanan yang dilakukan oleh warga Panti Asuhan dalam menjaga kebersihan akan memberikan dampak positif dan keterbiasaan anak-anak panti untuk menjaga lingkungan. 
Pendekatan pengelolaan sampah dilakukan melalui pendekatan berbasis 3R dan berbasis masyarakat, pengelolaan sampah secara terpadu dengan melaksanakan pengelolaan sejak dari sumbernya. Pengelolaan sampah anorganik dengan metode 3R (reduce, reuse dan recycle) dapat dilakukan tiap rumah (Christian et al., 2019). 3R adalah upaya yang meliputi kegiatan mengurangi (reduce), menggunakan kembali (reuse) dan mendaur ulang sampah (recycle) (Tarigan, 2013). Adapun proses 3R yang dapat dimulai dari rumah tangga: Reuse: memilih botol mineral untuk dijadikan tempat minyak goring. Reduce: menggunakan produk yang dapat diisi ulang, dan recycle: memilah sampah anorganik menjadi barang yang bermanfaat (Usman, 2016). Pendekatan tersebut dilakukan melalui pendidikan kesehatan dan permainan yang diikuti oleh anak-anak panti. Menurut World Health Organization (WHO) tahun 1984 pendidikan kesehatan yaitu mengubah perilaku dan lingkungan seseorang sebagai upaya untuk memfasilitasi ke arah perubahan perilaku tersebut (Nurmala et al., 2018).

Sosialisasi pemilihan sampah pada anak-anakdi Panti Asuhan Muhammadiyah Tanah Abang bertujuan untuk mengenalkan dan meningkatkan pengetahuan anak-anak panti dalam pemanfaatan kembali sampah, baik organik maupun anorganik diperkenalkan contoh yang dapat diaplikasikan serta diperkenalkannya bank sampah. Untuk pengurangan sampah diperkenalkan teknik-teknik sederhana seperti mengurangi kemasan, kembali pada pembungkus yang dapat terdegradasi. Untuk itu pengelolaan sampah sistem 3R (reduse, reuse, recycle), melalui pengumpulan, pemilahan, pengelolaan sampah oleh anak-anak panti harus terus disosialisasikan agar menjadi suatu kebiasaan sejak usia anak-anak.

\section{MASALAH}

Perubahan dan pembentukan perilaku individu dibutuhkan untuk pengelolaan sampah. Pembentukan perilaku individu dalam mengelola sampah yang benar perlu ditanamkan sejak usia anak-anak, yang merupakan usia emas. Pembentukan perilaku pada usia ini lebih mudah dan lebih terlihat hasilnya daripada usia berikutnya. Pembentukan perilaku mengelola sampah sejak usia dini ini dapat dimulai dari pembentukan kebiasaan memilah dan menempatkan sampah pada tempatnya. Diharapakan kebiasaan memilah dan menempatkan sampah pada tempatnya terus terbawa sehingga menjadi perilaku individu hingga dewasa. Karena mengelola sampah dan menciptakan lingkungan yang bersih dan sehat akan lebih mudah jika tertanam sejak dini (Amri \& Widyantoro, 2017).

Panti Asuhan Muhammadiyah Tanah Abang merupakan panti asuhan binaan Pengurus Cabang Muhammadiyah Tanah Abang. Panti Asuhan yang telah berdiri di akhir tahun 50-an ini menaungi anak-anak yatim dan dhuafa baik di sekitar daerah Tanah Abang maupun dari daerah lain. Berdasarkan observasi panti asuhan sudah memiliki 2 jenis tempat sampah berdasarkan fungsinya yaitu tempat sampah berwarna biru yang fungsinya untuk sampah organik, sampah basah seperti sisa-sisa makanan, dedaunan, dan lainnya. Tempat sampah berwarna orange yang fungsi sebenarya untuk sampah anorganik, sampah kering, kertas, kaleng, plastik, dan lainnya. Tempat sampah di panti juga masih terbatas dalam jumlahnya. Berdasarkan penggunaannya tempat sampah di panti belum sesuai dengan jenisnya. Anak-anak panti belum melakukan pemilihan sampah berdasarkan jenisnya. Hasil wawancara dari 5 orang anak, 3 orang anak tidak bisa menjawab pemilahan sampah organik dan anorganik. Dengan masalah tersebut muncullah ide untuk melakukan sosialisasi pemilihan sampah rumah tangga untuk meningkatkan 
pengetahuan anak-anak panti dalam pengolahan sampah di Panti Asuhan Muhammadiyah Tanah Abang.

\section{METODE PELAKSANAAN}

Pelaksanaan kegiatan pengabdian kepada masyarakat ini dilakukan pada hari Minggu, tanggal 8 Maret 2020 dari pukul 08.00-11.30 WIB di Panti Asuhan Muhammadiyah Tanah Abang di Jl. KH. Mas Mansyur RT 05/RW 09 Kec. Tanah Abang Jakarta - Pusat. Kegiatan ini diikuti oleh 14 anak-anak panti. Metode pelaksanaan kegiatan dibagi menjadi dua tahap yaitu: penyuluhan untuk meningkatkan pengetahuan dan permainan (games) untuk meningkatkan keterampilan. Pretest dan post-test diberikan di awal dan akhir kegiatan yang bertujuan untuk mengukur tingkat pengetahuan anak-anak panti.

Pengetahuan merupakan hasil dari tahu, dan ini terjadi setelah orang melakukan penginderaan terhadap suatu objek tertentu. Penginderaan terjadi melalui pancaindra manusia, yakni indera penglihatan, pendengaran, penciuman, rasa dan raba. Sebagian besar pengetahuan manusia diperoleh melalui mata dan telinga (Notoatmodjo, 2010). Chabot et al. (2014) menyatakan bahwa metode Pre-test dan post-test merupakan alat penilaian yang sangat dianjurkan untuk mengukur keberhasilan kemajuan suatu proses pembelajaran karena evaluasinya bersifat ringkas dan efektif. Pre-test diberikan sebelum penyuluhan dan bertujuan untuk mengetahui sejauh mana pengetahuan responden tentang materi yang akan diberikan. Fungsi Pre-test untuk melihat efektifitas penyuluhan. Sementara post-test diberikan setelah pemberian materi penyuluhan dengan tujuan untuk mengetahui sampai dimana pemahaman responden terhadap materi penyuluhan setelah kegiatan dilaksanakan (Ngalim, 2009). Metode pemberian materi dilakukan dengan metode yang lebih partisipatif, yaitu dengan mempraktekkan langsung.

\section{HASIL DAN PEMBAHASAN}

Kegiatan pengabdian masyarakat ini dilaksanakan di Panti Asuhan Muhammadiyah Tanah Abang, kegiatan ini diikuti oleh 14 orang anak-anak panti. Karakteristik responden yang diamati meliputi umur, jenis kelamin, dan tingkat pendidikan. tetapi hanya 12 orang anak yang mengisi pre dan post-test. Pre dan post-test terdiri dari 10 item pertanyaan yang terkait dengan jenis - jenis sampah, dampak permasalahan sampah dan beberapa upaya pemanfaatan sampah.

Berdasarkan tabel 1 karakteristik responden berdasarkan usia terbanyak yaitu usia 10 tahun sebanyak 4 orang anak (33\%), berdasarkan jenis kelamin jumlah responden perempuan sama dengan laki - laki yaitu sebanyak 6 orang anak (50\%). Tingkat pendidikan responden terbanyak yaitu sekolah dasar (SD) sebanyak 8 orang anak (66,7\%), sekolah lanjut tingkat pertama ( SLTP) sebanyak 3 orang anak (25\%), dan tingkat pendidikan sekolah lanjut tingkat atas (SLTA) sebanyak 1 orang anak $(8,3 \%)$. Pengetahuan anak-anakdinilai dari pengkategorian hasil pre dan post-test. Katagori kurang baik jika peserta mendapatkan skor kurang dari 60. Sedangkan, kategori baik jika peserta mendapatkan skor lebih dari 60. 
Tabel 1. Distribusi Karakteristik Anak-anak panti Asuhan Muhammadiyah Tanah Abang

\begin{tabular}{cccc}
\hline No. & Karakteristik Responden & Jumlah & Persentase \\
\hline 1 & Umur & & \\
& 10 th & 4 & 33.3 \\
11 th & 2 & 16.7 \\
12 th & 1 & 8.3 \\
13 th & 1 & 8.3 \\
& 14 th & 2 & 16.7 \\
& 15 th & 1 & 8.3 \\
& 18 th & 1 & 8.3 \\
& Jenis Kelamin & & \\
& Laki - laki & 6 & 50.0 \\
& Perempuan & 6 & 50.0 \\
& Tingkat Pendidikan & & \\
& SD & 8 & 66.7 \\
& SLTP & 3 & 25 \\
& SLTA & 1 & 8.3 \\
\hline
\end{tabular}

Berdasarkan Gambar 1 hasil Pre-test tingkat pengetahuan peserta terhadap pemilahan sampah kategori kurang baik sebanyak 4 orang anak $(33,3 \%)$ dan peserta dengan kategori baik tingkat pengetahuannya sebanyak 9 orang anak (66,7\%). Hasil post-test tingkat pengetahuan peserta terhaap pemilahan sampah kategori kurang baik menjadi 1 orang anak $(8,3 \%)$ dan kategori baik tingkat pengetahuan peserta menjadi 12 orang (91,7\%). Dari hasil Pre-test, terlihat bahwa sebagian besar anak-anak panti belum memahami dengan baik perbedaan istilah sampah organik dan anorganik. Namun anak-anak panti memiliki pengetahun mengenai bahaya sampah.

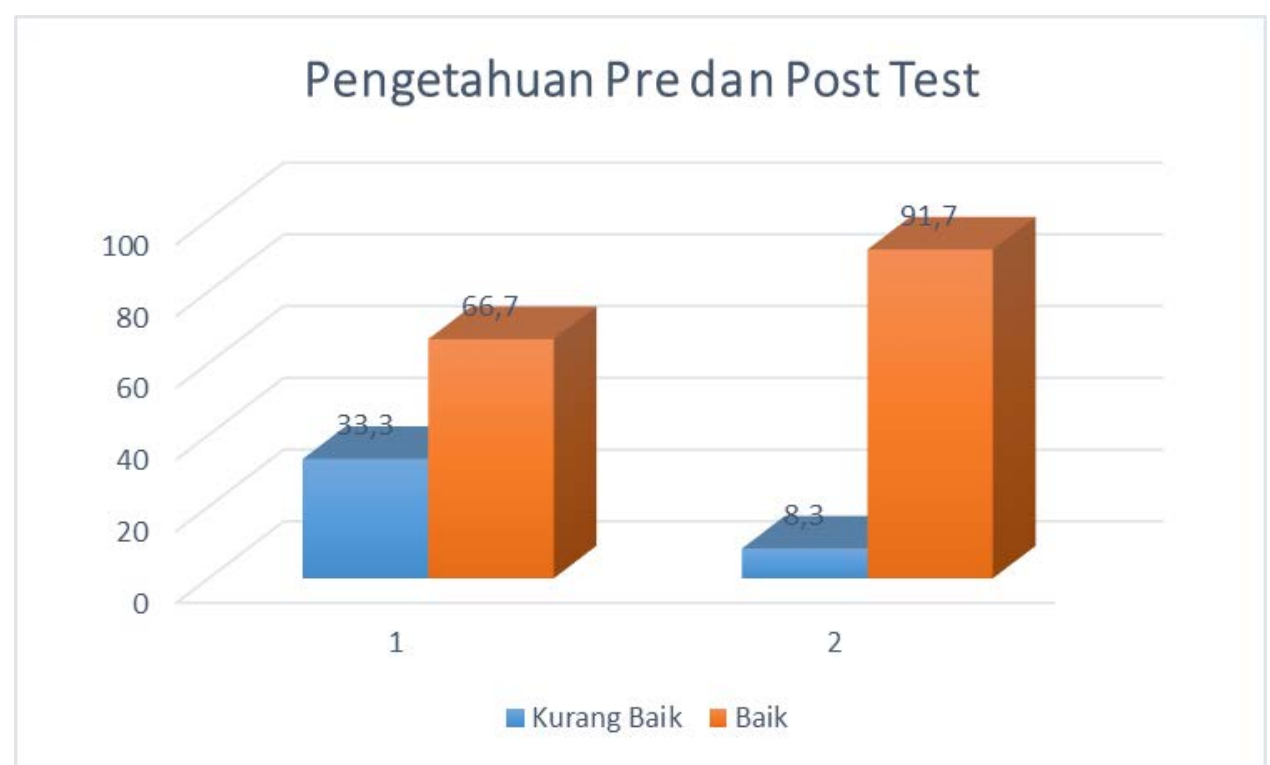

Gambar 1. Hasil Pre-test dan Post-test Anak-anak Panti Asuhan Muhammadiyah Tanah Abang

Selain pre dan post-test anak-anakmelakukan permainan pemilahan sampah yang bertujuan untuk mencairkan suasana dan mengevaluasi materi yang diberikan. Anak-anak diminta untuk 
menuliskan jenis sampah rumah tangga yang ada di lingkungan panti. Tiap individu menganalisa masing- masing 5 jenis sampah organik dan anorganik

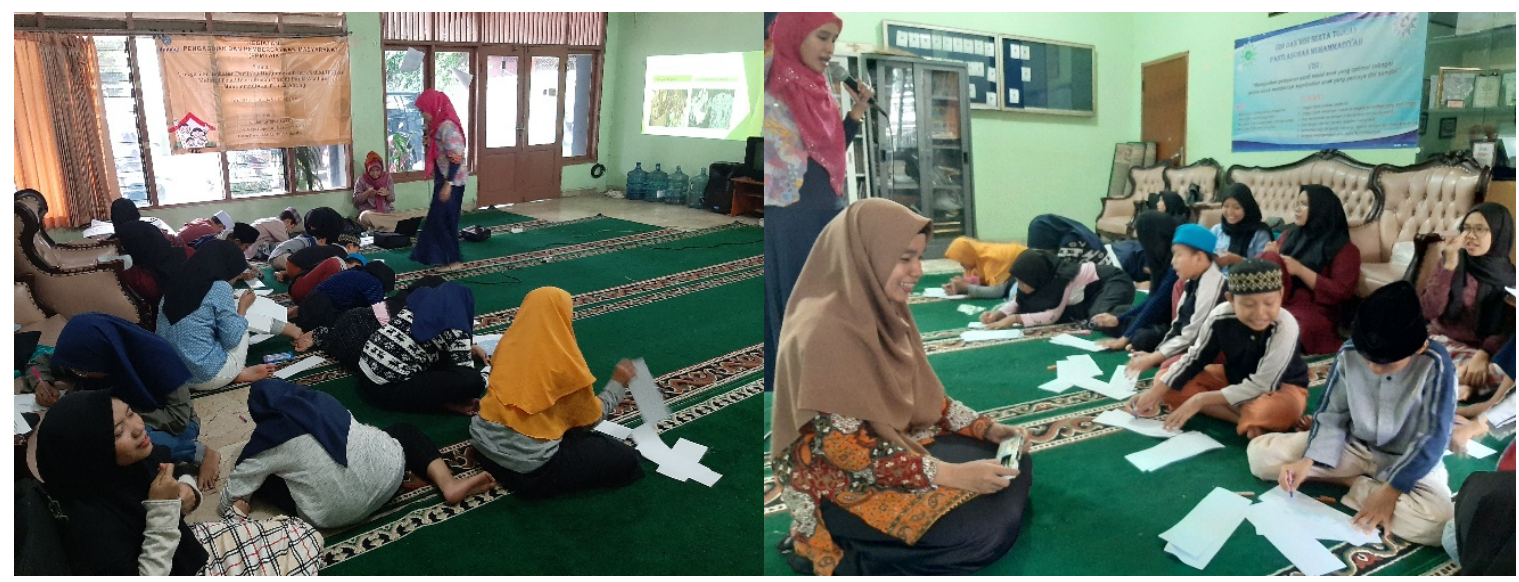

Gambar 2. Permainan Pemilahan Sampah

Setelah individu menuliskan 5 jenis sampah organik dan anorganik yang dihasilkan dari lingkungan panti, maka mereka menempelkan semua kertas ke kaca yang mereka tulis di depan peserta lain. Setelah itu mereka diberikan penjelasan mengenai sampah organik dan anorganik. Anak-anakkemudian secara sukarela menyebutkan dan menempelkan jenis sampah yang sudah mereka tulis dan tempel di depan peserta lain.

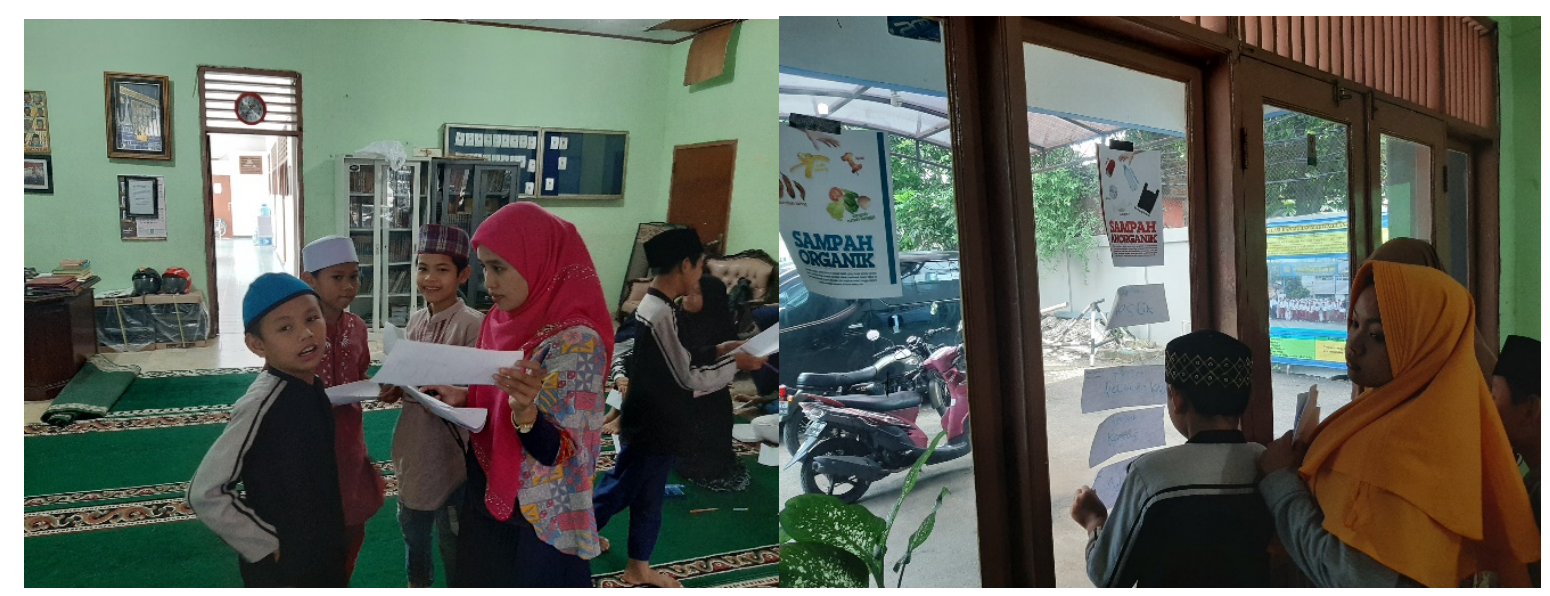

Gambar 3. Menyebutkan dan Menempelkan Sampah Berdasarkan Jenisnya

\section{KESIMPULAN}

Pengetahuan anak-anak Panti Asuhan Muhammadiyah Tanah Abang terhadap jenis sampah sudah sangat baik. Melalui permainan anak-anakdapat menyebutkan semua jenis sampah organik dan anorganik yang ada di lingkungan panti. Namun, sarana dan prasarana di Panti Asuhan Muhammadiyah Tanah Abang seperti kurangnya tempat sampah mempengaruhi sikap anak-anak terhadap pemilahan sampah. Kegiatan ini diharapakan dapat dilanjutkan dengan pelatihan pengolahan sampah baik itu pengolahan sampah organik dan anorganik, sehingga anakanak panti dapat melakukan upaya-upaya sederhana di panti yang dapat meningkatkan efektifitas dalam proses daur ulang di masyarakatnya. 


\section{UCAPAN TERIMA KASIH}

Terima kasih atas dukungan pendanaan Lembaga Pengabdian dan Pemberdayaan Masyarakat (LPPM) Universitas Muhammadiyah Prof Dr HAMKA (UHAMKA) serta Panti Asuhan Muhammadiyah Tanah Abang Jakarta Pusat sebagai mitra program ini.

\section{DAFTAR PUSTAKA}

Amri, C., \& Widyantoro, W. (2017). Pendampingan Pembelajaran Memilah dan Menempatkan Sampah pada Tempatnya Sejak Usia Dini Di TK Imbas 1. 1, 121-126.

Chabot, Costa, M., Chaffey, \& Cabrillo. (2014). Choosing the Right Assessment Method: Pre-test / Posttest Evaluation. 2.

Christian, S., Wahyu Irawati, ); Pendidikan, F. I., \& Biologi, P. (2019). Studi Penerapan Bank Sampah di Kota Yogyakarta. Jurnal Bioeksperimen, 5(1), 1-10. https://doi.org/10.23917/bioeksperimen.v5i1.2795

Dinas Lingkungan Hidup Kabupaten, D. L. H. . (2020). Website Portal Resmi Dinas Lingkungan Hidup dan Kebersihan Pemerintah Kabupaten Badung.

Goleman, Daniel, Boyatzis, Richard, Mckee, A., \& Perdana. (2018). Peraturan Daerah Provinsi Daerah Khusus Ibukota Jakarta No. 3 Th. 2013. Journal of Chemical Information and Modeling, 53(9), 1689-1699. https://doi.org/10.1017/CBO9781107415324.004

Intruksi Gubernur No. 107, T. 2019. (2019). Intruksi Gubernur Daerah Khusus Ibukota Jakarta No. 107 Th. 2019.

Istiqamah, S., Nim, E., Martoyo, H., Pardi, M. A., \& Ab, M. (2019). Pengelolaan Sampah Oleh Dinas Lingkungan Hidup Perumahan Rakyat dan Kawasan Permukiman dalam Mewujudkan Lingkungan Bersih Di Kota Putussibau Kabupaten Kapuas Hulu. 8.

Marliani, N. (2015). Pemanfaatan Limbah Rumah Tangga (Sampah Anorganik) Sebagai Bentuk Implementasi dari Pendidikan Lingkungan Hidup. Formatif: Jurnal Ilmiah Pendidikan MIPA, 4(2), 124-132. https://doi.org/10.30998/formatif.v4i2.146

Ngalim M, P. (2009). Prinsip - prinsip dan Teknik Evaluasi Pengajaran. Remaja Rosdakarya.

Notoatmodjo, S. (2010). Pendidikan dan Perilaku Kesehatan. Rineka Cipta.

Nurmala, I., Rahman, F., Nugroho, A., Erlyani, N., \& Laily, N. (2018). Promosi Kesehatan. Airlangga University Press.

Ramon, A., \& Afriyanto, A. (2017). Karakteristik Penanganan Sampah Rumah Tangga Di Kota Bengkulu. Jurnal Kesehatan Masyarakat Andalas, $10(1), \quad 24$. https://doi.org/10.24893/jkma.v10i1.159

Tarigan, P. B. (2013). Modul Pengolahan Sampah Berbasis 3R. In Journal of Chemical Information and Modeling (Vol. 53, Issue 9, pp. 1689-1699). https://doi.org/10.1017/CBO9781107415324.004

Taufiq, A., \& Maulana, M. F. (2015). Sosialisasi Sampah Organik Dan Non Organik Serta 
PelatUsman, S. (2016). Strategi Pengelolaan Sampah Rumah Tangga di Kota Tarakan Kalimantan Utara. Jurnal Ekonomi Pembangunan, 5(3), 349-359.ihan Kreasi Sampah. Inovasi Dan Kewirausahaan, 4(1), 68-73.

Usman, S. (2016). Strategi Pengelolaan Sampah Rumah Tangga di Kota Tarakan Kalimantan Utara. Jurnal Ekonomi Pembangunan, 5(3), 349-359. 